\title{
STRATEGI MANAJEMEN PADA STREET FOOD YOLKEE DI PUSAT KULINER PASAR LAMA TANGERANG
}

\author{
Hana Nathasya \\ Program Studi Magister Manajemen Universitas Tarumanagara \\ nathasyahana@gmail.com
}

\begin{abstract}
The purpose of this research is to analyze IFE, EFE, IE Matrix on Yolkee, and to find the strengths and weaknesses using SWOT analysis, and to know the right management strategy that can applied by Yolkee using QSPM. The type of research used in this study is qualitative descriptive approach. The data used in this research is primary data. The collection of data obtained from the field reaserch and study of literature. Results of this study showed the IFE, EFE, IE Matrix, SWOT analysis of Yolkee, and the management strategies that can applied by Yolkee by using QSPM.
\end{abstract}

Abstrak : Tujuan penelitian ini adalah untuk menganalisa penilaian IFE, EFE, dan IE Matriks pada Yolkee, mengetahui kekuatan dan kelemahan melalui analisis SWOT, serta mengetahui strategi manajemen yang tepat yang dapat diterapkan oleh Yolkee untuk menarik konsumen menggunakan QSPM. Jenis penelitian yang digunakan dalam penelitian ini adalah penelitian deskriptif dengan pendekatan kualitatif. Data yang digunakan adalah data primer. Pengumpulan data didapatkan melalui penelitian lapangan serta studi kepustakaan. Hasil dari penelitian ini menunjukkan analisis IFE Matriks, EFE Matriks, IE Matriks, dan SWOT pada Yolkee, serta beberapa strategi manajemen yang tepat untuk diterapkan pada Yolkee menggunakan QSPM.

Keywords : IFE Matriks, EFE Matriks, IE Matriks, SWOT, QSPM

\section{PENDAHULUAN}

Tujuan utama dari sebuah perusahaan tak lain adalah memperoleh keuntungan yang sebesar-besarnya dari produk atau jasa yang ditawarkan. Ada banyak aspek yang dapat menyokong perusahaan untuk memperoleh keuntungan finansial tersebut, salah satunya adalah dari strategi manajemen yang diterapkan oleh perusahaan tersebut.

Makanan merupakan kebutuhan pokok manusia. Dari waktu ke waktu, industri kuliner menunjukkan perkembangan yang signifikan. Kreativitas manusia dalam menciptakan berbagai jenis makanan menjadi salah satu pendorong pertumbuhan industri kuliner.

Yolkee merupakan stand street food yang menjajakan kentang goreng, kulit ayam, dan ayam goreng tepung yang disajikan dalam tiga varian saus, antara lain saus telur asin, saus barbekyu, dan saus keju sebagai menunya. Yolkee sendiri berdiri di Pusat Kuliner Pasar Lama Tangerang. Yolkee harus dapat menentukan dan mengimplementasikan strategi manajemen yang baik guna meningkatkan daya beli konsumen. Untuk dapat merumuskan strategi ini, ada beberapa alat yang dapat dipergunakan untuk menganalisa lingkungan internal dan eksternal dari Yolkee, antara lain adalah EFE (External Factor Evaluation) Matrix, IFE (Internal Factor Evaluation) Matrix, IE (Internal External) Matrix, SWOT Matrix dan QSPM (Quantitive Strategic Planning Matrix).

\section{TINJAUAN PUSTAKA \\ Manajemen Strategi}

Thomas Wheelen dkk (2010:105) mengatakan bahwa manajemen strategi adalah serangkaian dari pada keputusan manajerial dan kegiatan-kegiatan yang menentukan keberhasilan perusahaan dalam jangka panjang. 


\section{Wisata Kuliner}

Menurut Undang-undang Kepariwisataan Nomor 9, tahun 1990, Bab I Pasal 1, wisata adalah kegiatan perjalanan atau sebagian dari kegiatan tersebut yang dilakukan secara sukarela serta bersifat sementara untuk menikmati obyek dan daya tarik wisata. Sedangkan, kuliner erat kaitannya dengan makanan.

\section{Jajanan Jalanan (Street Food)}

Menurut Keputusan Menteri Kesehatan Republik Indonesia Nomor 942/Menkes/SK/VII/2003, makanan jajanan adalah makanan dan minuman yang diolah oleh pengrajin makanan di tempat penjualan dan atau disajikan sebagai makanan siap santap untuk dijual bagi umum selain yang disajikan jasa boga, rumah makan atau restoran, dan hotel.

\section{External Factor Evaluation (EFE) Matrix}

EFE Matrix merupakan sebuah strategi untuk merangkum dan mengevaluasi faktorfaktor eksternal antara lain ekonomi, sosial, budaya, demografi, lingkungan alam, politik, pemerintahan, hukum, teknologi, dan informasi persaingan (Kristianti, 2017:21).

\section{Internal Factor Evaluation (IFE) Matrix}

Matriks evaluasi faktor internal (Internal Factor Evaluation - IFE) merupakan perangkat formulasi strategi yang meringkas serta mengevaluasi kekuatan dan kelemahan utama dalam fungsi-fungsi perusahaan. Hal tersebut juga memberikan dasar untuk mengidentifikasi dan mengevaluasi hubungan di antara fungsi-fungsi ini (David, 2016:111).

\section{Matrix Internal External (IE)}

Matriks IE dapat dibagi menjadi tiga bagian besar dengan implikasi strategi yang berbeda. Pertama, rumus untuk divisi yang berada di sel I, II, atau IV dapat dijelaskan sebagai tumbuh dan dibangun. Strategi intensif (penetrasi pasar, integrasi ke depan, dan integrasi horizontal) atau integratif (integrasi ke depan, integrasi ke belakang, dan integrasi horizontal paling sesuai untuk divisi-divisi ini. Kedua, divisi-divisi yang berada di sel III, V, atau VII dapat dikelola paling baik dengan strategi ditahan dan dijaga; penetrasi pasar dan pengembangan produk adalah dua strategi yang umum digunakan untuk tipe divisi-divisi ini. Ketiga, rumus umum untuk divisi-divisi VI, VII, atau IX adalah panen atau divestasi (David, 2016:181).

\section{SWOT Matrix}

Menurut Pearce dan Robinson (2015), analisis SWOT adalah sebuah teknik yang memudahkan para manajer dalam meninjau situasi strategi suatu perusahaan.

\section{Quantitive Strategic Planning Matrix (QSPM)}

Menurut David (2016, 185), QSPM adalah alat yang memungkinkan penyusun strategi untuk mengevaluasi faktor kunci internal.

\section{METODE PENELITIAN}

Dalam penelitian ini, jenis penelitian yang digunakan adalah peneltian deskriptif yaitu metode penelitian yang dilakukan melalui pengamatan untuk mendapatkan keteranganketerangan terhadap suatu masalah tertentu.

Menurut David (2017), terdapat beberapa tahapan dalam menganalisis dan memilih strategi, yaitu: The Input Stage yang terdiri dari External Factor Evaluation (EFE) Matrix dan Internal Factor Evaluation (IFE) Matrix, The Matching Stage yang terdiri dari Internal External (IE) Matrix dan Strength-Weakness-Opportunity-Threat (SWOT) Matrix dan The Decision Stage yang terdiri dari Quantitative Strategic Planning Matrix (QSPM). 
HASIL ANALISIS DATA

Tabel 1.1

IFE Matriks pada Yolkee

\begin{tabular}{|l|c|c|c|}
\hline \multicolumn{1}{|c|}{ Faktor-Faktor Internal Utama } & Bobot & Rating & Skor Bobot \\
\hline Kekuatan: & & & \\
1. Produk buatan sendiri & 0,134 & 3 & 0,402 \\
2. Harga terjangkau & 0,179 & 4 & 0,716 \\
3. Lokasi strategis & 0,134 & 4 & 0,536 \\
4. Terdaftar di Go-Food & 0,080 & 3 & 0,24 \\
5.Mempunyai ciri khas tersendiri & 0,161 & 3 & 0,483 \\
\hline Kelemahan: & & & \\
1. Kapasitas tempat relatif kecil & 0,071 & 1 & 0,071 \\
2. SDM yang terbatas & 0,107 & 2 & 0,214 \\
3. Produk mudah ditiru & 0,134 & 1 & 0,134 \\
\hline Total & 1,00 & & 2,796 \\
\hline
\end{tabular}

Dengan perolehan total skor bobot di atas rata-rata yaitu 2,796, menunjukkan bahwa Yolkee memiliki posisi kekuatan internal dalam persaingan pasar industri kuliner lebih besar daripada faktor kelemahannya.

Tabel 1.2

EFE Matriks pada Yolkee

\begin{tabular}{|l|c|c|c|}
\hline \multicolumn{1}{|c|}{ Faktor-Faktor Eksternal Utama } & Bobot & Peringkat & Skor Bobot \\
\hline Peluang: & & & \\
1. Sektor kuliner semakin diminati & 0,203 & 3 & 0,609 \\
2. Peluang membuka franchise & 0,186 & 3 & 0,558 \\
3. Pemanfaatan media sosial & 0,119 & 3 & 0,357 \\
\hline Ancaman: & & & \\
1. Banyak pesaing & 0,186 & 2 & 0,372 \\
2. Faktor cuaca & 0,085 & 2 & 0,17 \\
3. Harga bahan baku tinggi & 0,220 & 3 & 0,660 \\
\hline Total & 1,00 & & 2,726 \\
\hline
\end{tabular}

Dari data EFE Matriks di atas, total skor bobotnya adalah 2,726. Total skor bobot tersebut memiliki nilai di atas rata-rata, artinya Yolkee memiliki respon di atas rata-rata terhadap peluang dan ancaman dalam industri kuliner sehingga Yolkee mampu memanfaatkan peluang dan mengatasi ancaman dengan baik. 


\section{SKOR IFE (2,796)}

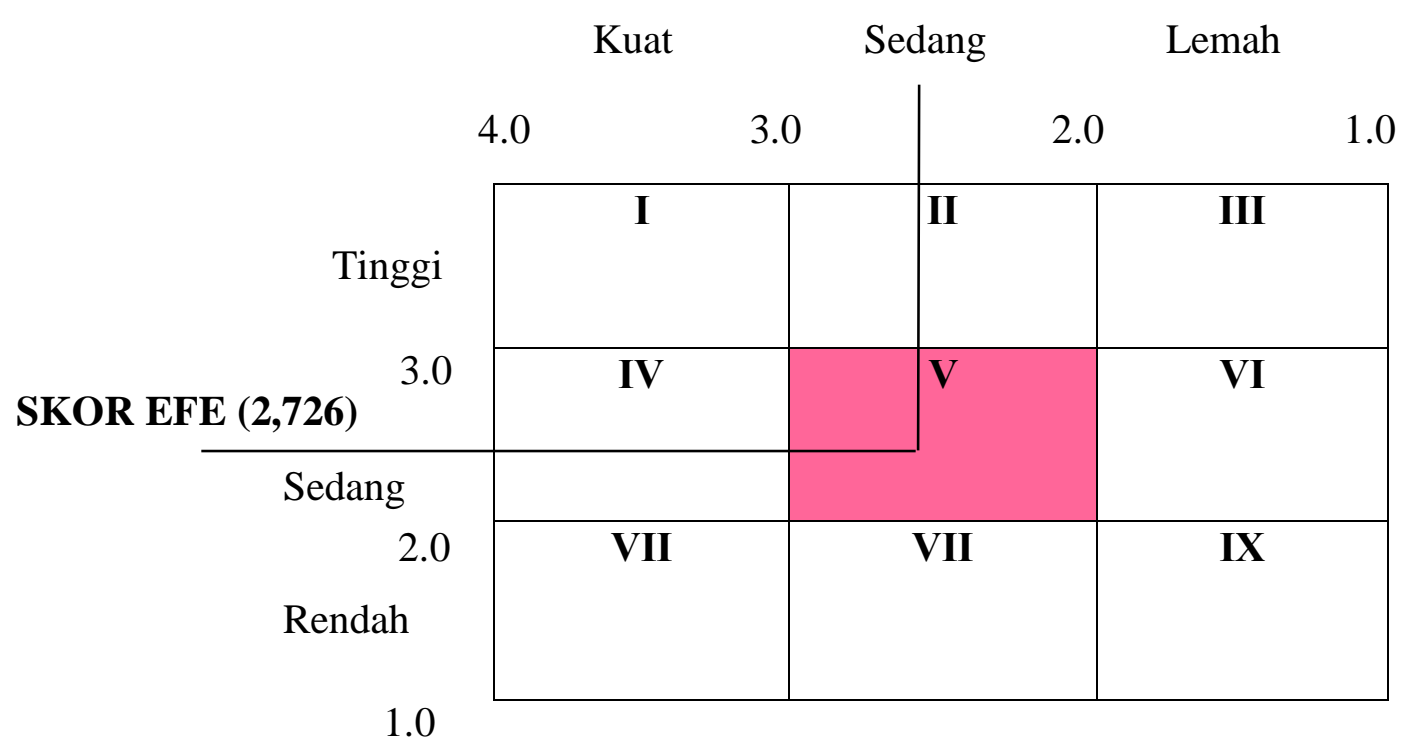

\section{Gambar 5.1 \\ Matriks IE pada Yolkee}

Hal tersebut menunjukkan posisi Yolkee berada pada sel V. Pada posisi tersebut, strategi yang tepat adalah menjaga dan mempertahankan.

Tabel 5.3.

Analisis SWOT pada Yolkee

\begin{tabular}{|c|c|c|}
\hline SW & $\begin{array}{l}\text { Strength: } \\
\text { 1. Produk buatan sendiri } \\
\text { 2. Harga terjangkau } \\
\text { 3. Lokasi strategis } \\
\text { 4. Terdaftar di Go-Food } \\
\text { 5. Mempunyai ciri khas }\end{array}$ & $\begin{array}{l}\text { Weakness: } \\
\text { 1. Kapasitas tempat kecil } \\
\text { 2. SDM terbatas } \\
\text { 3. Produk mudah ditiru }\end{array}$ \\
\hline $\begin{array}{l}\text { Opportunities: } \\
\text { 1. Sektor kuliner semakin } \\
\text { diminati } \\
\text { 2. Peluang membuka } \\
\text { franchise } \\
\text { 3. Pemanfaatan media } \\
\text { sosial }\end{array}$ & $\begin{array}{l}\text { SO Strategies: } \\
\text { 1. Membuka cabang/franchise } \\
\text { (S1, S5, O1, O2) } \\
\text { 2. Meningkatkan pemasaran } \\
\text { melalui media sosial } \\
\text { (S4, O3) } \\
\text { 3. Menambah produk baru } \\
\text { (S1, S5, O1, O2, O3) } \\
\text { 4. Memberikan promosi kepada } \\
\text { konsumen } \\
\text { (S1, S2, O1, O3) }\end{array}$ & $\begin{array}{l}\text { WO Strategies: } \\
\text { 1. Menambah tenaga kerja } \\
\text { (W2, O1, O2) } \\
\text { 2. Menambah produk baru } \\
\text { (W3, O3) } \\
\text { 3. Memperluas tempat } \\
\text { (W1, O1, O2) }\end{array}$ \\
\hline $\begin{array}{l}\text { Threats: } \\
\text { 1. Banyak pesaing } \\
\text { 2. Faktor cuaca } \\
\text { 3. Harga bahan baku tinggi }\end{array}$ & $\begin{array}{l}\text { ST Strategies: } \\
\text { 1. Berinovasi dengan produk baru } \\
\text { (S1, S4, S5, T1) } \\
\text { 2. Mendesain tempat agar } \\
\text { terlindung dari hujan } \\
\text { (S3, T2) } \\
\text { 3. Mengoptimalkan penggunaan } \\
\text { bahan baku } \\
(\mathrm{S} 1, \mathrm{~S} 2, \mathrm{~T} 3)\end{array}$ & $\begin{array}{l}\text { WT Strategies: } \\
\text { 1. Memperluas dan mendesain } \\
\text { tempat } \\
\text { (W1, T2) } \\
\text { 2. Membuat inovasi produk } \\
\text { baru } \\
\text { (W3, T1, T3) } \\
\text { 3. Meningkatkan kinerja outlet } \\
\text { (W2, T1) }\end{array}$ \\
\hline
\end{tabular}


Pada tabel diatas dapat dilihat alternatif-alternatif strategi yang diperoleh dari matriks SWOT kemudian diolah untuk merumuskan strategi-strategi yang dapat dipakai untuk menghadapi ancaman eksternal dan kelemahan internal yang dihadapi.

Tabel 5.5.

\section{Hasil Analisis QSPM}

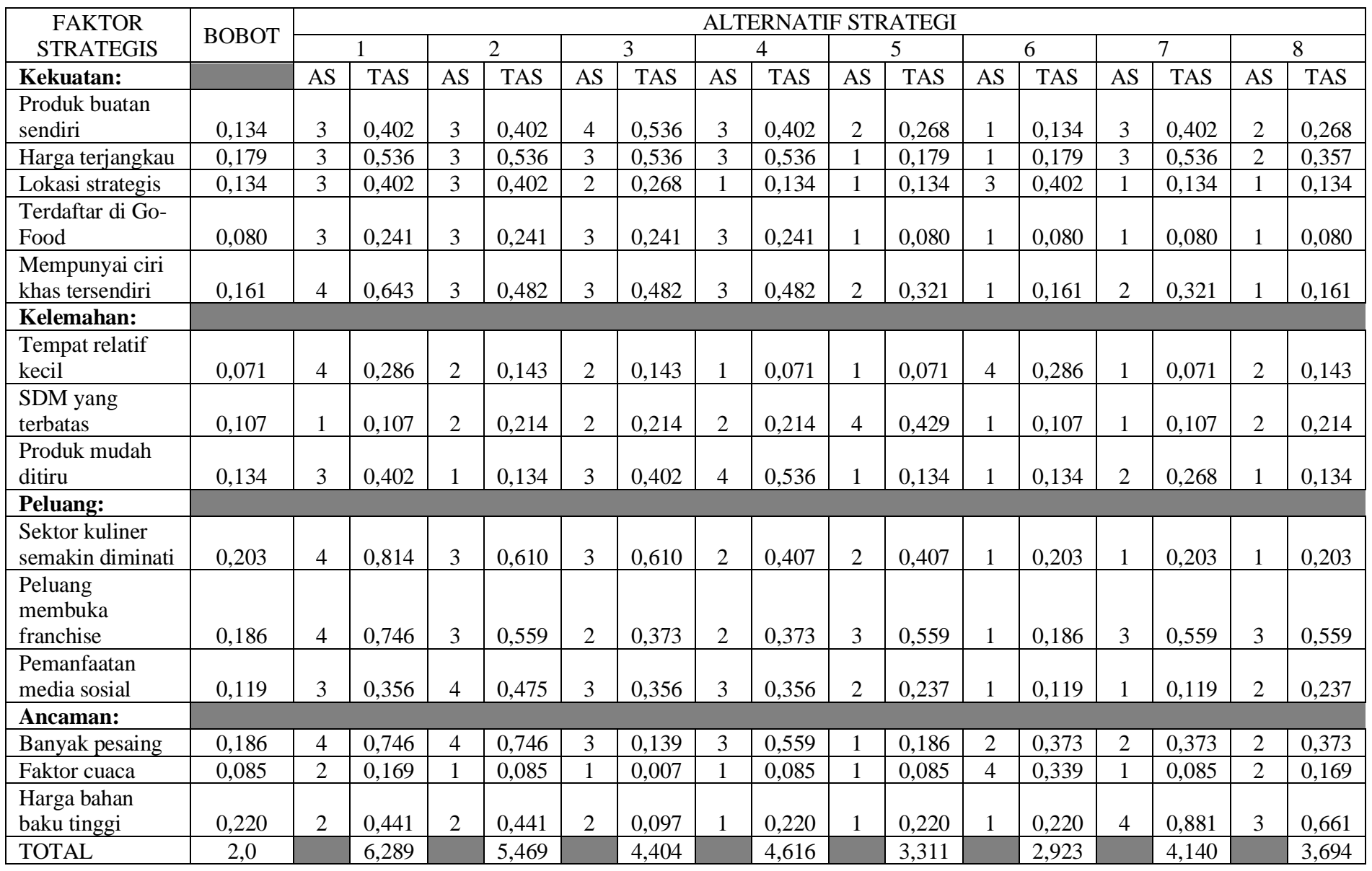

Setelah melakukan perhitungan Total Attractive Score, maka dapat disimpulkan bahwa strategi yang menjadi prioritas untuk dilakukan oleh Yolkee adalah membuka cabang/franchise dengan TAS sebesar 6,289.

\section{KESIMPULAN DAN SARAN}

Dari hasil penelitian pada bab pembahasan, dapat disimpulkan bahwa strategi yang paling efektif bagi Yolkee untuk diterapkan adalah membuka cabang/franchise dengan perolehan Total Attractive Score sebesar 6,289. Manajemen perusahaan juga dapat mempertimbangkan beberapa alternatif strategi lainnya yang memiliki nilai perolahan TAS cukup tinggi, misalnya meningkatkan pemasaran melalui media sosial, atau memberikan promosi kepada konsumen.

\section{DAFTAR PUSTAKA}

David, M.E., 2009. The quantitative strategic planning matrix (QSPM) applied to retail computer store. The Coastal Business Journal. pp 42-52

David, Fred R dan Forest R. David. 2016. Manajemen Strategik: Suatu Pendekatan Keunggulan Bersaing Edisi 15. Jakarta: Salemba Empat.

Kristianti, Rina Adi. 2017. Manajemen Strategik. Tangerang: Pustaka Mandiri. 
Pearce, J.A.II, Robinson, R.B., 2015. Strategic Management: Planning for Domestic \& Global Competition. $14^{\text {th }}$ Edn. McGraw-Hill Companies

Republik Indonesia, Keputusan Menteri Kesehatan Republik Indonesia Nomor 942/Menkes/SK/VII/2003.

Republik Indonesia, Undang - Undang Kepariwisataan Nomor 9 Tahun 1990 Bab I Pasal 1.

Wheelen, T.L., et al. 2015. Strategic Management and Business Policy. Pearson 